\title{
Emergency physicians and public health experts call for tight regulations on cannabis edibles and concentrates
}

— Cite as: CMAJ 2019 January 28;191:E111-2. doi: 10.1503/cmaj.109-5703

Posted on cmajnews.com on Jan. 8, 2019.

H

otly anticipated since the Cannabis Act (C-45) paved the way for the legalization of recreational marijuana products, the second act began with the government's recent release of draft regulations for cannabis edibles and concentrates. These products are set to become legal for sale by Oct. 17, 2019, and amendments to existing regulations "to address the public health and public safety risks of these new classes of cannabis" must be brought into force by that date.

Now the public consultation process begins, with health care professionals jockeying for position - alongside marijuana industry executives and government officials - to ensure public health and safety concerns make their way into the legislation.

On the front lines of health care, emergency room physicians are bracing for an influx of patients to a system already overburdened by the opioid crisis. In Colorado, which legalized recreational marijuana in 2014, the bulk of the spike in cannabis-related emergency visits were the result of edibles -toddlers and children ingesting them accidentally, or adolescents and adults suffering severe physical and psychological effects.

"Based on the Colorado experience, we're hoping the regulations are proactive," said Dr. Atul Kapur, co-chair of a public affairs committee for the Canadian Association of Emergency Physicians. "We're looking for public education in advance of the products coming onto the market, and rules that make these products secure so children and toddlers don't have access to them."
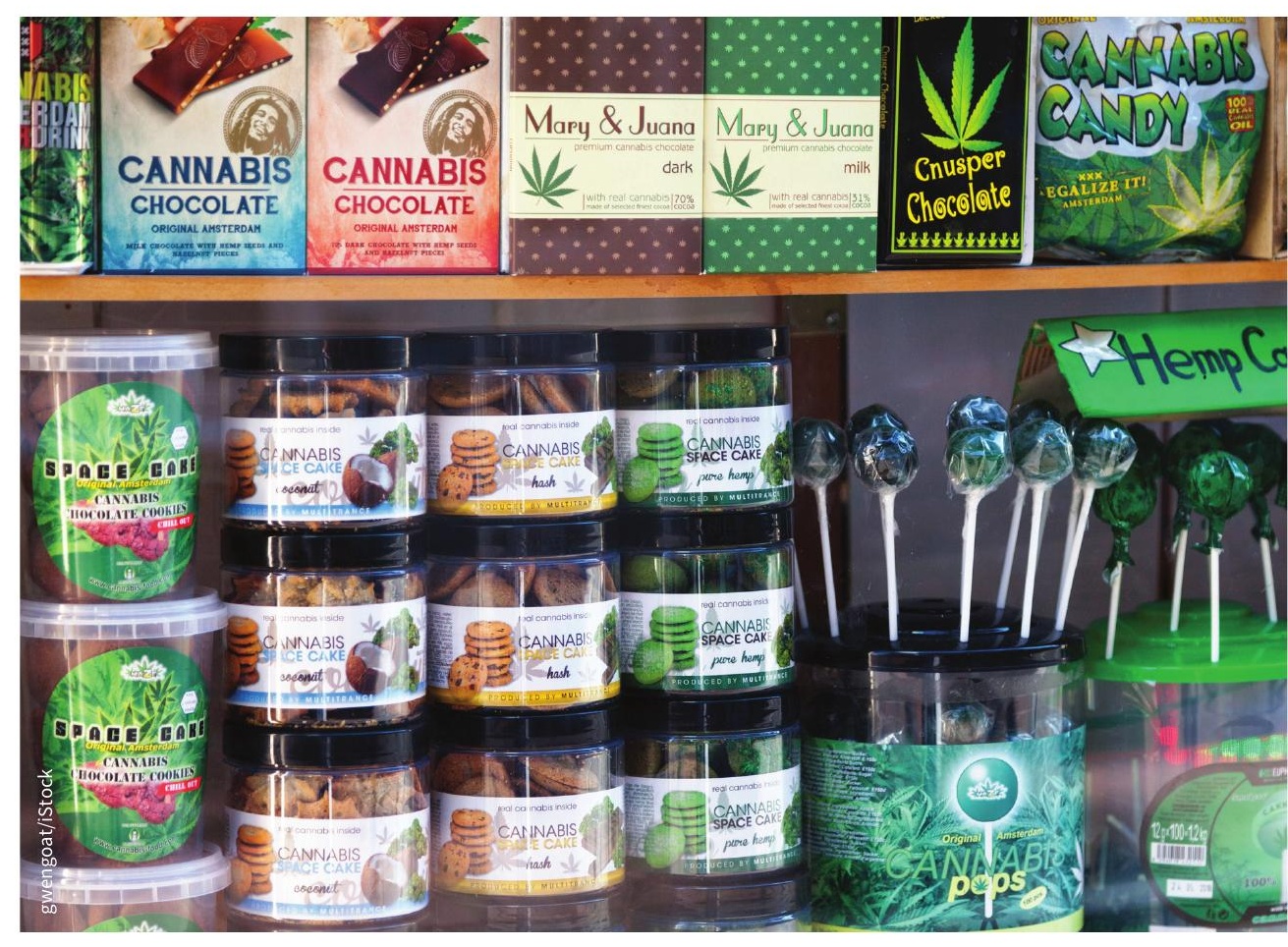

Public health experts want Canadian regulations on cannabis edibles to set limits on the range of products allowed for sale.

Federal and provincial governments must anticipate the adverse effects of the policy change and budget for the health care system's response, he warns. "Emergency rooms are dealing with so many issues relating to substance abuse. This is one, but it's one on top of everything else going on - it's another straw on the camel's back that might already have some fractures."

Kapur's warnings were echoed by Dr. Margaret Thompson, medical director of the Ontario Poison Centre, and her colleague Heather Hudson, a registered nurse and interprofessional education specialist. They expect the number of calls to the centre will increase substantially after legislation on edibles, saying the products tend to be mistaken for safe, child-friendly foods and, once allowed in homes legally, more curious children may end up ingesting them.

The Canadian Public Health Association (CPHA) is one of many groups pushing for tight regulation of edibles. "An over-riding concern is that industry pressure on politicians may result in a watering down of the regulations or an 
over-expansion of the range of products that are permitted," according to Ian Culbert, CPHA's executive director.

He says his organization has narrowed its advocacy to four issues. They want the final version of the regulations to set limits on tetrahydrocannabinol (THC) concentrations, meet plain packaging requirements, clearly state portion sizes and restrict the range of products available.

From a harm-reduction approach, Culbert notes, there is good rationale for legalizing and regulating "consumables" as their consumption avoids some of the health risks associated with smoking cannabis. But that decision must come with increased public education and health promotion initiatives so people understand the difference between smoking cannabis and consuming it in an alternative format. "A wide range of education is required from the proper storage of edibles, and all cannabis products, to consumption information for new consumers."

Although health care professionals and policymakers remain wary, the food industry considers edibles to be an opportunity. Companies already involved with alcohol distribution see themselves as set up to organize the rollout of a host of new products and brands. "The route to market for recreational cannabis is exactly the same as alcohol, so it's a natural fit for wine and spirits distributors to expand into cannabis," said Lisa Campbell, CEO of Lifford Cannabis Solutions, a subsidiary of Lifford Wine \& Spirits.
Like the health care sector, the food industry is keen to see regulations that will clarify labeling, but it will also be pushing for restaurants and bars to be permitted to participate with infused edibles and beverages. "If we can have tiramisu for dessert infused with alcohol, we should be able to have cannabis-infused dinners and desserts at restaurants across Canada. Until the food service industry and cannabis events are included in regulations, there will continue to be a grey market," said Campbell. "That's not good for consumer safety due to concerns around packaging and dosing."

Sarah Brown, Ottawa, Ont. 